\title{
AS RELIGIÕES AFRO-BRASILEIRAS NO MERCADO RELIGIOSO E OS ATAQQUES DAS IGREJAS NEOPENTECOSTAIS
}

\author{
Paulo Eduardo Angelin*
}

\section{Resumo}

O objetivo deste artigo é o de discutir acerca da perda de adeptos do conjunto das religiões afro-brasileiras, bem como sobre os ataques sofridos pelo candomblé e umbanda, efetuados principalmente pelas igrejas neopentecostais. A discussão se orientará pela seguinte problemática: quais são as principais fragilidades das religiões afro-brasileiras que estão possibilitando a perda de adeptos e os constantes e agressivos ataques dos neopentecostais? Para tanto, se torna necessário na introdução, historicizar e contextualizar a questão religiosa no Brasil, evidenciando o status de religião oficial do catolicismo desde o descobrimento até o advento da República, e seu declínio com a possibilidade instaurada da liberdade e do pluralismo religioso. Para atingir os propósitos deste artigo, esta análise basear-se-á em textos de autores bastante familiarizados com a presente discussão e especialistas em sociologia da religião.

Palavras-chave: Religiões Afro-brasileiras. Candomblé. Umbanda. Igrejas Neopentecostais.

\section{Introdução da temática}

O presente artigo tem como objetivo específico analisar e discutir acerca das principais fragilidades das religiões afro-brasileiras que possibilitam a perda de adeptos e os constantes e agressivos ataques das religiões neopentecostais.

Historicamente, o Brasil sempre foi um país culturalmente católico. Segundo Nunes (2004), a história da formação da nação brasileira e de seu povo confunde-se com a história da implantação de uma religião, o catolicismo, que surgiu como única religião tolerável pelo Estado no país, ostentando este título por cerca de 300 anos, até o advento da República em 1889, que norteada por princípios de laicidade promoveu uma nova realidade. O catolicismo 
neste longo período foi reconhecido pelo Estado como a religião oficial do país, e todas as outras formas de manifestação de fé eram severamente reprimidas pela força policial. Este foi o caso das religiões afro-brasileiras. Assim, conta-nos Prandi (2004), que todo o indivíduo que vivia no Brasil, incluindo-se os negros, era obrigado a se declarar católico. Deste modo, os negros que recriaram no Brasil as religiões africanas, agiam como católicos, até mesmo após o advento da República, no final do século XIX, momento em que o catolicismo deixou de ser a única religião tolerada do país. Desse modo, desde o início, as religiões afrobrasileiras valorizaram os ritos e sacramentos da Igreja Católica, caracterizando-se como religião sincrética.

Após o advento da República, o catolicismo continuou sendo a religião da imensa maioria da população. Mas a liberdade religiosa, conquistada a partir deste momento, colocou a possibilidade do exercício de outros cultos e credos, bem como a possibilidade da pluralidade religiosa, antes inimaginável no Brasil. Desde esse momento, “os terreiros lugares de culto do candomblé e da macumba - deixam de ser o que foram até então: casos de polícia” (NUNES, 2004: p.30). Diante da possibilidade de liberdade religiosa e do enorme crescimento do mercado religioso, o catolicismo no país começou efetivamente a diminuir de tamanho. Só para se ter uma ideia, segundo Pierucci (2004), o censo demográfico realizado pelo IBGE em 1970, e divulgado dois anos mais tarde, apontou que cerca de $92 \%$ da população brasileira (uma população de 70 milhões de habitantes) se declararam católicos. Por sua vez, mais recentemente, de acordo com o censo demográfico de 2000, a proporção de católicos brasileiros declarados havia caído para 73,8\%, um pouco menos de três quartos da população total do país, estimada em 170 milhões de habitantes. Enfim, ainda que seja a maioria da população brasileira católica, o número de católicos diminuiu consideravelmente.

Algumas explicações para tal fato são ofertadas por especialistas no assusto e colaboram substancialmente para com o nosso entendimento. Para Pierucci (2004), em sociedades pós-tradicionais, como é o caso do Brasil, as filiações tradicionais, inclusive as religiosas, acabam decaindo substancialmente e abrem oportunidades para outras filiações religiosas. Sendo assim, o destino histórico do catolicismo será cada vez mais o declínio. Isso ocorre devido ao grande processo de transformação ocorrido no país, que se transformou numa sociedade livre, com uma cultura cada vez mais plural que respira a liberdade religiosa. Por sua vez, Nunes (2004) afirma que vivemos numa sociedade onde ocorreu e vêm ocorrendo mudanças significativas, fato este que exige mudanças radicais, também na religião e na igreja. Nesse sentido, quem mais sofre são as religiões tradicionais, no caso brasileiro, a católica e, mais especificamente, as religiões afro-brasileiras. No ponto de vista de Nunes, 
todo este processo é fruto da defasagem entre a cultura moderna e seus valores presentes na sociedade brasileira, e da afirmação de certas normas e valores religiosos que estão desvinculados e que não contemplam essa cultura. Basta pararmos para pensar e encontraremos alguns exemplos dessa defasagem apresentada pelo autor: a não aceitação pela igreja católica do uso de preservativos, pílulas anticoncepcionais; do casamento de homossexuais; da discussão sobre o aborto etc. A Igreja católica não está aberta para as mudanças e reivindicações da sociedade atual. Na visão de Brito (2004, p.44), "sem refontalizar-se, a Igreja Católica não conseguirá se libertar de suas estruturas históricas. Hoje ela é prisioneira do seu passado”.

Ainda de acordo com Nunes (2004), diante da vasta diversidade religiosa, o catolicismo passou a ser uma entre tantas outras possibilidades de aderir à fé. Nesse cenário todo, os protestantes, liderados pelos pentecostais e mais recentemente pelos neopentecostais, são os principais beneficiários, devido a sua maior capacidade de se adequar às exigências da sociedade em transformação. De acordo com Pierucci (2004), para os evangélicos, no seu conjunto, as taxas de crescimento desde os anos de 1980 foram altíssimas, mas foi, sobretudo nos anos 1990, que eles tiveram uma enorme expansão, crescendo cerca de 100\% em uma década, mostrando-se capazes de disputar adeptos no intenso mercado religioso. Se por um lado, as igrejas evangélicas, lideradas principalmente pelas igrejas neopentecostais se colocaram no mercado religioso como fortes concorrentes na disputa por fiéis, sobretudo a partir dos anos de 1990, ajudando a elevar o declínio do catolicismo no Brasil, por outro lado, as religiões afro-brasileiras em seu conjunto, além de serem alvos de constantes ataques efetuados por igrejas neopentecostais, vêm progressivamente perdendo adeptos diante de sua incapacidade de se colocar como forte concorrente no mercado religioso.

\section{As religiões afro-brasileiras e os ataques das igrejas neopentecostais: origem, desenvolvimento e declínio do Candomblé e da Umbanda}

Os ritos africanos que cultuam os orixás e outras divindades africanas foram iniciados no Brasil a partir de meados do século XVI por negros africanos escravizados durante o processo de colonização (SIQUEIRA, 2009). Contudo, de acordo com Prandi (2004), o candomblé teve sua origem na Bahia e constituiu-se, até a metade do século XX, uma instituição de resistência cultural à escravidão e aos mecanismos de dominação da sociedade branca e eminentemente cristã, mecanismos estes que por um longo período marginalizaram os negros africanos e os afro-brasileiros até mesmo após a abolição da escravatura, que 
ocorreu em 1888. Inicialmente, constituída como religião de preservação cultural-étnico, o candomblé, já no final da década de 1940 e início de 1950, transformou-se numa religião de dimensão universal, desprendendo-se, portanto das “amarras étnicas, raciais, geográficas e de classes sociais” (PRANDI, p. 223, 2004).

Por sua vez, já no início do século XX, formou-se uma nova religião afro-brasileira no Rio de Janeiro, que recebeu a denominação de umbanda. A umbanda nasceu a partir da síntese do candomblé bantu e de caboclo, que foram transportados da Bahia para o Rio de Janeiro e criou o discurso que prometia ser a única religião afro-brasileira capacitada para ser universal e estar presente em todo o Brasil. “Chamada de a 'religião brasileira' por excelência, a umbanda juntou o catolicismo branco, a tradição dos orixás da vertente negra, símbolos, espíritos e rituais de referência indígena, inspirando-se, assim, nas três fontes básicas do Brasil mestiço” (PRANDI, 2004, p.223). Por outro lado, no curso da década de 1960, o candomblé reagiu ao grande fervor da umbanda e se colocou como um importante concorrente da nova religião afro-brasileira. Por meio de um processo de transformação, se adaptando às novas condições culturais e sociais, o candomblé alargou seus laços territoriais, se expandindo da Bahia para todo o Brasil, além de acrescentar a si uma classe intelectualizada do Rio de Janeiro e São Paulo, que valorizava a cultura negra-baiana, fato responsável por uma grande parcela de sua legitimidade social. Mais recentemente, o candomblé requereu para si a constituição como religião autônoma, abandonando os símbolos, práticas e crenças católicas, um movimento chamado de africanização do candomblé (PRANDI, 2004).

Apesar de todas as transformações no cenário das religiões afro-brasileiras, especialmente no candomblé, resultados da busca pela legitimação social, pelo crescimento e pelo reconhecimento como religiões universais, na atualidade, o conjunto dos afro-brasileiros passam por dificuldades, como, por exemplo, a perda de adeptos. De acordo com Prandi (2004), em 1980, cerca de $0,6 \%$ da população se declaravam membros das religiões afrobrasileiras. Já em 1991, apenas 0,4\% da população. E mais recentemente, baseando-se no censo de 2000, Prandi nos informa que, apenas 0,3\% da população no Brasil declaram-se membros das religiões afro-brasileiras, o que corresponde a pouco mais de 470 mil seguidores, números que vêm revelando o declínio do segmento das religiões afro-brasileiras. Se não bastasse o problema da perda de adeptos do conjunto das religiões afro-brasileiras, nos tempos atuais, o candomblé e a umbanda continuam sofrendo agressões e perseguições, agora não mais por órgãos oficias, mas pelos seus rivais neopentecostais, e seguem sobre enorme preconceito. Deste modo, é comum, mesmo atualmente quando a liberdade da escolha 
religiosa já faz parte da vida brasileira, muitos seguidores das religiões afro-brasileiras ainda se declararem católicos. Isso faz com que as religiões afro-brasileiras apareçam subestimadas nos censos oficias do Brasil (PRANDI, 2004, p. 225).

Enfim, o “declínio” do conjunto das religiões afro-brasileiras não se resume apenas às suas condições históricas. Existem outras razões que revelam a sua queda, como, especialmente, as novas condições da expansão das religiões no Brasil no contexto do mercado religioso e os ataques das igrejas neopentecostais. Passemos agora a analisar em linhas gerais estes aspectos negativos.

\section{O mercado religioso e suas novas condições para a expansão das religiões no brasil}

De acordo com Prandi (2004), o mercado religioso atualmente impõe mudanças constantes em seu cenário, que nem sempre as religiões afro-brasileiras conseguem assumir. Ainda muito agarradas às suas tradições, elas não conseguem se atualizar e entrar no mercado religioso de modo competitivo e enfrentar os seus “concorrentes” que, muitas vezes, agem de forma agressiva e impiedosa, crescendo à custa das religiões afro-brasileiras, com ataques aos deuses e entidades do candomblé e da umbanda. Por isso, existe a urgente necessidade das religiões afro-brasileiras se expandirem mais fortemente para se colocarem no mercado religioso como instituições competitivas com as demais religiões existentes no país, especialmente com as neopentecostais, que nas últimas décadas vêm crescendo rápida e fortemente.

Além do problema dos ataques dos neopentecostais, como veremos mais adiante, as religiões afro-brasileiras enfrentam outras dificuldades: sua própria estrutura e organização. Segundo Prandi (2004), grande parte da fragilidade das religiões afro-brasileiras está em sua própria constituição, como reunião não organizada e dispersa de grupos pequenos, que são os terreiros. Ao contrário das religiões de massa, como é o caso da católica e, especialmente, das neopentecostais, que a partir dos anos 80 do século passado transportaram suas reuniões religiosas para grandes templos e igrejas, localizados em regiões de grande visibilidade, fluxo intenso e contínuo de pessoas, bem como começaram a utilizar a mídia, principalmente o rádio e a televisão para oferecerem seus cultos, disponibilizando às pessoas, de forma imediata e fácil, seus discursos religiosos, além de treinarem seus pastores para uma pregação uniforme e imediatista (como é o caso das igrejas evangélicas neopentecostais), e criarem grandes espetáculos para uma quantidade enorme de pessoas em missas dançantes celebradas 
por padres cantores (no caso da igreja católica), as religiões afro-brasileiras nunca promoveram toda essa transformação realizada pelos mais bem sucedidos grupos religiosos. O candomblé e a umbanda não são capazes de massificar suas reuniões a este ponto, e isso devido à própria vida religiosa que se pauta pelo desempenho de papéis sacerdotais dentro de um grupo com características familiares. Suas cerimônias são secretas e não abertas até mesmo aos membros do terreiro que não passaram por uma seleção baseada nos níveis iniciáticos.

Ainda segundo Prandi, esse massacre imposto pelo mercado religioso é mais visível na umbanda do que no candomblé, já que ela vem perdendo adeptos constantemente por não conseguir se adaptar às novas demandas impostas pela sociedade. Por sua vez, o candomblé, embora seja um século mais antigo do que a umbanda, tem se mostrado mais ágil para se adequar aos novos tempos, promovendo mutações em seu interior na busca pela expansão. $\mathrm{O}$ candomblé vem passando por profundas mudanças desde o final do século XX, e sua mais marcante transformação foi a sua universalização, passando de uma religião étnica para a religião de todos, incorporando novos adeptos da classe média e de origem não africana, promovendo mudanças importantes em sua base social. No entanto, apesar do esforço do candomblé, no conjunto geral, as religiões afro-brasileiras nitidamente sofrem com o massacre de outras religiões por não conseguirem se inserir de forma competitiva no mercado religioso.

Enfim, o conjunto das religiões afro-brasileiras constitui-se, no cenário atual, de religiões fragmentadas em pequenos grupos, caracterizadas pela ausência de uma organização ampla. Elas não se expõem e não buscam angariar adeptos por meio da mídia ou templos enormes e majestosos, localizados em locais de grande fluxo de pessoas. E, por isso, segundo Prandi, elas têm poucas chances de saírem melhor na competição desigual com outras religiões. "Silenciosamente, assistimos hoje a um verdadeiro massacre das religiões afrobrasileiras” (PRANDI, 2004: p. 231). Sem um projeto de reorganização e expansão para se colocar de modo competitivo no mercado religioso, as religiões afro-brasileiras tendem ao aniquilamento. E, a religião que “não muda, não sobrevive” (PRANDI, 2004: p. 233).

\section{Os ataques efetuados pelas igrejas neopentecostais sobre as religiões afro- brasileiras}

Segundo Prandi (2004), além de enfrentar o problema de sua própria estrutura e organização para se inserirem no mercado religioso, as religiões afro-brasileiras enfrentam 
hoje, principalmente, a concorrência e a violência física e simbólica das igrejas neopentecostais. As religiões afro-brasileiras finalmente não são mais perseguidas pelos órgãos oficiais e estão em paz com a polícia nos tempos atuais, devido à possibilidade de liberdade religiosa existente no Brasil, mas enfrentam inimigos dispostos a expulsá-las do cenário religioso, adversários que fazem da perseguição às crenças afro-brasileiras um ato de fé, o que pode ser testemunhado tanto nos templos e igrejas neopentecostais, como nos horários comprados na televisão e no rádio. De acordo com o referido autor, muitas igrejas neopentecostais, com frequência, submetem “desertores” da umbanda e do candomblé a rituais de exorcismo em cerimônias transmitidas pela televisão, com o objetivo de humilhar as entidades espirituais afro-brasileiras, supostamente incorporadas, as quais eles consideram manifestações do demônio.

Por sua vez Silva (2004), afirma que os neopentecostais, representados fortemente pela Igreja Universal do Reino de Deus, Deus é Amor, Igreja Internacional da Graça e outras, utilizam-se constantemente de um discurso que diz que é necessário eliminar a presença e a manifestação do demônio no mundo e adotam, com frequência, uma estratégia de classificar as outras congregações religiosas de pouco participar desse desígnio. Acusam, inclusive, algumas denominações religiosas, mais especificamente, as religiões afro-brasileiras, de favorecimento ao demônio, propiciando espaços privilegiados para ele se manifestar disfarçadamente em divindades cultuadas nesses sistemas, onde deuses são vistos como manifestação do demônio.

Silva (2004) tenta entender a escolha das igrejas neopentecostais em atacar as religiões afro-brasileiras, já que, num primeiro momento, tal investida carece de sentido, visto que, segundo os dados do censo do IBGE de 2000, as denominações afro-brasileiras agregam apenas $0.3 \%$ da população. Pergunta ainda se o melhor ataque não seria contra o catolicismo que, segundo o próprio IBGE, representa cerca de 73,7\% da população. De acordo com o autor, a investida aberta contra o catolicismo torna-se mais complicada e onerosa diante do monopólio religioso da igreja católica e de seus fortes vínculos construídos historicamente com diversos setores da sociedade. Nesse combate, ainda que nas últimas décadas o catolicismo venha perdendo fiéis, ele sairia vitorioso e fortalecido, produzindo até mesmo uma imagem negativa das igrejas neopentecostais. Nesse sentido, os ataques às religiões mais frágeis e menos estruturadas se justificam.

Silva revela inúmeros exemplos de ataques neopentecostais às religiões afrobrasileiras. O primeiro deles consiste em ataques feitos no âmbito dos cultos das igrejas neopentecostais, onde são realizadas, com frequência, sessões de exorcismo de entidades 
originárias das religiões afro-brasileiras, onde inicialmente são chamadas a incorporar e, em sequência, são desqualificadas e expulsas do corpo do fiel, revelando a sua libertação espiritual. "Dos púlpitos, este ataque estende-se aos programas religiosos transmitidos pela Rede Record (de propriedade da IURD) e por outras emissoras que têm seus horários comprados pelas igrejas neopentecostais” (2004: p.217).

Também são comuns agressões contra terreiros e seus membros. Não é raro, de acordo com Silva, membros das igrejas neopentecostais invadirem terreiros com o objetivo de destruírem altares, quebrarem imagens e “exorcizarem” seus frequentadores, resultando, quase que sempre, em agressões físicas, pancadarias e casos de polícia. Do mesmo modo, são frequentes os ataques dos neopentecostais a cerimônias religiosas afro-brasileiras realizadas em locais públicos ou a seus símbolos. Segundo o autor, quando os eventos das religiões afrobrasileiras são realizados em espaços públicos, seus adeptos ficam mais expostos aos ataques, que vão desde distribuição de panfletos ao público presente que propagam contra esses eventos, até a tentativa de interrupção forçada dos rituais. E, se não bastasse tudo isso, os símbolos das religiões afro-brasileiras, colocados nos locais públicos, frequentemente são alvos de ataques de fanáticos religiosos neopentecostais que não aceitam a diversidade religiosa e vêem essas imagens como símbolos que representam o diabo.

Por outro lado, esclarece o autor, as reações dos religiosos afro-brasileiros vêm crescendo nos últimos anos diante dos ataques dos neopentecostais, embora ainda estejam muito longe de representar um movimento articulado que faça frente ao movimento bem articulado e estruturado dos evangélicos. Existe uma necessidade de reação cada vez mais forte e organizada para buscar a preservação da aceitação e da legitimidade conquistada duramente junto à sociedade brasileira. É certo, porém, que os primeiros passos já foram dados. Várias ações judiciais foram impetradas pelos líderes das religiões afro-brasileiras contra pastores e suas igrejas neopentecostais que insistem em atacar publicamente as religiões afro-brasileiras, afirmando que são demoníacas e as desqualificando, sendo que muitas dessas ações vêm dando algum resultado favorável aos impetrantes, ao ponto que algumas igrejas neopentecostais, bem como as redes de televisão que exibem programas ofensivos estão sendo notificadas e punidas. 


\title{
Considerações finais
}

O objetivo deste artigo foi o de discutir acerca da perda de adeptos do conjunto das religiões afro-brasileiras, bem como sobre os ataques sofridos pelo candomblé e pela umbanda, efetuados pelas igrejas neopentecostais. O que pudemos concluir neste trabalho, a partir da análise dos autores especialistas no assunto em questão, é que o declínio do conjunto das religiões afro-brasileiras não está relacionado apenas às suas condições históricas, mas ocorre, também, em decorrência de pelo menos duas razões: às novas condições da expansão das religiões no Brasil no contexto do mercado religioso e os ataques das igrejas neopentecostais. Diante disso, é certo que o desenvolvimento, o fortalecimento e a aceitação definitiva das religiões afro-brasileiras dependem cada vez mais da criação de estratégias de sobrevivência no mercado religioso, buscando se adaptar gradativamente a ele e às exigências da sociedade e dos fiéis, bem como da elaboração de estratégias inteligentes de reação aos ataques efetuados pelas igrejas neopentecostais, além de construir diálogos diante das condições adversas.

\section{AFRO-BRAZILIAN RELIGIONS IN THE RELIGION MARKET AND THE ATTACK BY NEO-PENTECOSAL CHURCHES}

\begin{abstract}
The purpose of this article is to discuss the evasion of members of a group of Afro-Brazilian religions and the attacks suffered by candomble and umbanda, mainly by neo-Pentecostal churches. The discussion addresses the following issue: which are the most significant weaknesses of Afro-Brazilian religions that are leading to the evasion of their members and to constant and aggressive attacks by the neo-Pentecostal? For that purpose, it is necessary to introduce, historicize and contextualize religion in Brazil, evidencing the status of Catholicism as the official religion since the Discovery until the creation of the Republic, and its decline when religious freedom and pluralism was implemented. In order to reach their goal, this study is based on texts by authors that are familiar with the discussion at hand and with religion sociology.
\end{abstract}

Key words: Afro-Brazilian religions; candomble; umbanda; neo-Pentecostal churches. 


\section{Referências}

BRITO, Ênio José da Costa. Agonia de um modelo. In: SOUZA, Beatriz Muniz de; MARTINO, Luís Mauro Sá (orgs.) Sociologia da religião e mudança social: católicos, protestantes e novos movimentos religiosos no Brasil. São Paulo: Paulus, 2004, p. 37-46.

NUNES, Maria José Rosado. O catolicismo sob o escrutínio da modernidade. In: SOUZA, Beatriz Muniz de; MARTINO, Luís Mauro Sá (orgs.) Sociologia da religião e mudança social: católicos, protestantes e novos movimentos religiosos no Brasil. São Paulo: Paulus, 2004, p.22-36.

PIERUCCI, Antônio Flávio. Secularização e declínio do catolicismo. In: SOUZA, Beatriz Muniz de; MARTINO, Luís Mauro Sá (orgs.) Sociologia da religião e mudança social: católicos, protestantes e novos movimentos religiosos no Brasil. São Paulo: Paulus, 2004, p.13-21.

PRANDI, Reginaldo. O Brasil com axé: candomblé e umbanda no mercado religioso. In: Estudos Avançados (18) 52, 2004.

SILVA, Vagner Gonçalves da. Neopentecostalismo e religiões afro-brasileiras: significados do ataque aos símbolos da herança religiosa africana no Brasil contemporâneo. In: Mana. Estudos de Antropologia Social, Rio de Janeiro, Museu Nacional, 13 (1), 2004, pp 207-236.

SIQUEIRA, Sônia Aparecida de. Multiculturalismo e Religiões Afro-brasileiras. O Exemplo do Candomblé. In: Revista de Estudos da religião. São Paulo, PUC, Março, (9), 2009, pp. 3655. Disponível em: <http://www.pucsp.br/rever/rv1_2009/t_siqueira.pdf>. 